\title{
Aspectos biológicos e moleculares de amostras uropatogênicas de Escherichia coli isoladas na Cidade do Rio de Janeiro
}

\author{
Biological and molecular characteristics of uropathogenic Escherichia coli strains \\ isolated in the City of Rio de Janeiro
}

\author{
Carmen Macedo Esparis ${ }^{1}$, Lúcia Martins Teixeira ${ }^{2}$, Kinue Irino ${ }^{3}$, Paola F. Gil ${ }^{1}$, Monica M.T. \\ Barros Almeida ${ }^{4}$, Guilherme Santoro Lopes ${ }^{4}$, Vera Lúcia R. Bravo ${ }^{1}$, Raquel S. Pacheco ${ }^{5}$ \\ e Adriana Hamond Regua-Mangia ${ }^{1}$
}

\begin{abstract}
RESUMO
Amostras uropatogênicas de Escherichia coli isoladas de indivíduos moradores de localidades distintas na Cidade do Rio de Janeiro, foram caracterizadas quanto o sorotipo, propriedades hemolíticas e hemaglutinantes, susceptibilidade a antimicrobianos e perfil isoenzimático. O método molecular empregado associado com a investigação de marcadores de urovirulência, permitiu detectar uma grande diversidade entre os isolados. Entretanto, foi observada uma relação mais estreita entre amostras de Escherichia coli epidemiologicamente relacionadas.
\end{abstract}

Palavras-chaves: Escherichia coli. Infecção urinária. Marcadores de urovirulência. Isoenzima.

\begin{abstract}
Uropathogenic Escherichia coli strains isolated from individuals living in different areas of the City of Rio de Janeiro were characterized according to serotype, hemolytic properties, hemagglutination properties, antimicrobial susceptibility and isoenzymatic profile. The molecular approach used, together with investigation of urovirulence markers, enabled detection of great diversity among the isolates. However, closer relationships were observed between epidemiologically related Escherichia coli samples.
\end{abstract}

Key-words: Escherichia coli. Urinary infection. Urovirulence markers. Isoenzyme.

A Escherichia colié uma das principais causas de doenças infecciosas em seres humanos e é o agente etiológico mais frequiente das infecções do trato urinário (ITUs), acometendo principalmente mulheres e crianças ${ }^{8}$. Determinantes específicos de urovirulência têm sido descritos e associados com o desenvolvimento de ITUs e a manifestação de quadros clínicos específicos ${ }^{59}$. Estudos epidemiológicos têm revelado que este potencial uropatogênico é um atributo de subpopulações bacterianas, carreadoras de propriedades específicas de virulência caracterizando assim clones patogênicos ${ }^{6}{ }^{10}$. Além dos fatores diretamente relacionados com a urovirulência destes patógenos, a resistência a antimicrobianos tem sido apontada como um fenômeno entre os mais relevantes, cuja evolução vem sendo gradativamente observada ${ }^{6}{ }^{911}$. Com o objetivo de esclarecer aspectos biológicos e epidemiológicos destes microrganismos circulantes em nosso meio, amostras uropatogênicas de Escherichia coli foram caracterizadas quanto ao sorogrupo/sorotipo, produção de hemolisina, propriedade hemaglutinante, resistência a antimicrobianos e perfil isoenzimático. Foram incluídas 40 amostras de $E$. coli isoladas, no período de 1999 a 2004, de indivíduos com infecção urinária sintomática e assintomática, moradores de localidades diversas no Rio de Janeiro. As amostras bacterianas foram isoladas de 19 indivíduos

\footnotetext{
1. Departamento de Ciências Biológicas da Fundação Oswaldo Cruz do Rio de Janeiro, Rio de Janeiro, RJ. 2. Departamento de Microbiologia Médica da Universidade Federal do Rio de Janeiro, Rio de Janeiro, RJ. 3. Seção de Bacteriologia do Instituto Adolfo Lutz, São Paulo, SP. 4. Departamento de Medicina Preventiva do Hospital Universitário da Universidade Federal do Rio de Janeiro, Rio de Janeiro, RJ. 5. Departamento de Bioquímica e Biologia Molecular da Fundação Oswaldo Cruz, Rio de Janeiro, RJ.

Endereço para correspondência: Dra. Adriana Hamond Regua-Mangia. Dept ${ }^{o}$ de Ciências Biológicas/ENSP/FIOCRUZ. R. Leopoldo Bulhões 1480, Manguinhos, 21041-210 Rio de Janeiro, RJ.

Tel: 5521 2564-8985

e-mail: regua@ensp.fiocruz.br

Recebido para publicação em 25/3/2006

Aceito em 4/12/2006
} 
(homens, mulheres grávidas/não grávidas e crianças), atendidos no Centro de Saúde Escola Germano Sinval Faria Escola Nacional de Saúde Pública/Fundação Oswaldo Cruz e de 21 pacientes adultos (16 mulheres e 5 homens) com quadros clínicos definidos (pielonefrite-33\%, ITU baixa-33\% e infecção urinária assintomática-28,5\%), atendidos no Serviço Ambulatorial do Hospital Universitário/UFRJ.

A atividade hemolítica foi observada a partir do crescimento das amostras a $37^{\circ} \mathrm{C}$ por $18-24 \mathrm{~h}$, em placas contendo agar de tripticaseína de soja (TSA-BBL) acrescido de 5\% de sangue desfibrinado de carneiro. Durante a semeadura, foram feitas picadas em profundidade no meio de cultura com auxílio de alça bacteriológica, a fim de facilitar a detecção da expressão da atividade hemolítica. A formação de halos de hemólise total ao redor das colônias bacterianas foi classificada como $\beta$-hemólise, enquanto a lise parcial das hemácias foi definida como $\alpha$-hemólise. Amostras não hemolíticas foram caracterizadas pela ausência de halo de hemólise. Para os ensaios de hemaglutinação, foi empregado sangue desfibrinado de carneiro, cabra, coelho e de cobaio, a $5 \%$ em PBS ( $\mathrm{pH} 7,2)$, previamente lavado e mantido a $4^{\circ} \mathrm{C}$. Suspensões bacterianas $\left(5 \times 10^{9} \mathrm{CFU} / \mathrm{ml}\right.$ em PBS, $\left.\mathrm{pH} 7,2\right)$ foram preparadas a partir de crescimento a $37^{\circ} \mathrm{C}$ por $18-24 \mathrm{~h}$ em placas contendo TSA. Para a reação, $25 \mu$ l dos eritrócitos foram misturados a $25 \mu \mathrm{l}$ da suspensão bacteriana $\left(5 \times 10^{9}\right.$ $\mathrm{CFU} / \mathrm{ml}$ em PBS, pH 7,2), após crescimento a $37^{\circ} \mathrm{C}$ por 18 $24 \mathrm{~h}$ em placas contendo agar de tripticaseína de soja (TSA$\mathrm{BBL})$. Os testes foram realizados em placas de polipropileno, sob agitação, na presença e na ausência de D-manose, a 5\% em PBS (pH 7,2) e mantidos a $4^{\circ} \mathrm{C}$ até o momento da leitura. A hemaglutinação (HA) foi considerada manose-resistente (MRHA), quando ocorria na presença de manose e manosesensível (MSHA), quando a atividade era inibida ou reduzida na presença de manose. Para o controle dos testes de HA, foi incluída uma amostra padrão 108I-ETEC/CFA/I ${ }^{+}$. Para determinação dos antígenos somáticos $(0)$ e flagelares $(\mathrm{H})$, amostras bacterianas cultivadas em meios de motilidade sólido e semi-sólido (Difco, Becton Dickson, USA), foram submetidas a testes de aglutinação em tubo empregando-se anticorpos específicos (01 a 0181 e $\mathrm{H} 1$ a H56), preparados na Seção de Bacteriologia do Instituto Adolfo Lutz. A investigação da susceptibilidade a antimicrobianos foi realizada através de testes de difusão em ágar, conforme recomendações do NCCLS (2004), utilizando discos impregnados com: ácido nalidíxico (ANL-30 $\mu \mathrm{g}$ ), amicacina

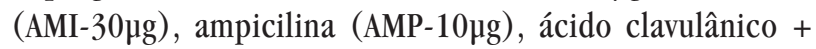

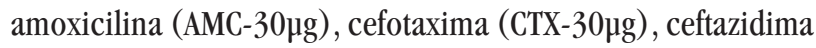

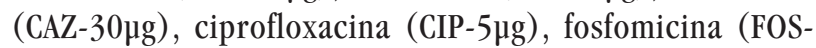
$200 \mu \mathrm{g})$, gentamicina (GEN-10 $\mu \mathrm{g})$, nitrofurantoína (NIT$300 \mu \mathrm{g})$, piperacilina + tazobactam (PPT-110 $\mu \mathrm{g})$, sulfazotrim (SUT-25 $\mu$ g) e trimetoprim (TRI-5 $\mu$ g). Para o controle de qualidade dos testes de susceptibilidade foram incluídos os seguintes padrões: E. coli ATCC 25922, E.coli ATCC 35218, P. aeruginosa ATCC 27853 e $S$. aureus ATCC 25923. Para a análise do perfil isoenzimático foram investigados 10 sistemas enzimáticos: malato dehidrogenase, E.C.1.1.1.3.7 (MDH); aconitase, E.C.4.2.1.3 (ACO); adenilato kinase, E.C.2.7.4.3 (ADK); isocitrato dehidrogenase, E.C.1.1.1.42 (IDH); fenilalanil-leucina, E.C.3.4.11.1 (PEP-2); álcool dehidrogenase, E.C.1.1.1.1 (ADH); glucose fosfato isomerase, E.C.5.3.1.9 (GPI); glucose 6-fosfato, E.C.1.1.1.49 (G6PDH); glucose 6-fosfato dehidrogenase, E.C.1.1.1.44 (PGD) e fosfoglucomutase, E.C.2.7.5.1 (PGM). Para a análise numérica, foi utilizado o programa NTSYS-pc e o coeficiente Dice de similaridade. A ausência de atividade foi assumida como atividade nula para a enzima em questão.

A hemolisina é um fator de urovirulência presente em amostras de $E$. coli, disponibilizando ferro e favorecendo a destruição de células epiteliais e fagocíticas ${ }^{8}$. Em nosso estudo, a atividade hemolítica foi detectada em todas as amostras, expressando os tipos alfa (65\%) e beta (35\%). Os dois tipos hemolíticos foram detectados tanto em indivíduos atendidos no CSEGSF/ENSP/FIOCRUZ, quanto em pacientes atendidos no HU/UFRJ com quadro de pielonefrite e infecção urinária assintomática. Entre as amostras isoladas de casos de ITU baixa, foi observado apenas o tipo hemolítico alfa. A expressão de adesinas com propriedade de hemaglutinação manose-resistente (MRHA), tem sido associada com a manifestação de quadros clínicos específicos ${ }^{12}$. Dentre as amostras isoladas de pacientes atendidos no HU/UFRJ, a MRHA foi detectada apenas entre aqueles com quadro de pielonefrite e infecção urinária assintomática. Esses resultados corroboram dados de estudos prévios, sugerindo que as adesinas mediadoras desta propriedade constituem um fator de risco para o desenvolvimento da pielonefrite em pacientes assintomáticos. A capacidade de determinadas amostras bacterianas em induzir a MRHA frente a eritrócitos diversos, evidencia a expressão de adesinas distintas na superfície de suas células 5 . Tal propriedade foi também associada com a expressão do tipo hemolítico beta, sugerindo que a urovirulência destes patógenos seja de natureza multifatorial. Por outro lado, a MSHA, propriedade atribuída a fímbria tipo I, foi observada em $17,5 \%$ de amostras isoladas de pacientes sintomáticos e assintomáticos. Embora amplamente distribuída em populações de $E$. coli, a fímbria tipo I tem sido detectada em ITUs, especialmente, nas infecções do trato urinário baixo ${ }^{9}$. Os resultados da sorotipagem são compatíveis com a literatura, revelando uma população de natureza diversa $a^{4}$. Os sorogrupos $06(30,7 \%)$ e 075 (19,2\%), foram os mais freqüentes dentre os 12 0-grupos identificados nas 26 amostras 0-tipáveis. Duas foram rugosas e 12 0-não tipáveis (ONT). Os antígenos flagelares mais freqüentes foram H31 (21,7\%) e H10/H1 $(8,7 \%)$. Variantes imóveis foram detectadas em $37,5 \%$ da população bacteriana. Dos 19 sorotipos detectados, o 06:H31 e o 075:H- foram os prevalentes $(10 \%)$. Nas amostras pertencentes a um mesmo sorotipo, foi observado uma correlação do tipo hemolítico expresso com a capacidade de induzir a hemaglutinação. Além da associação com quadros clínicos particulares, fatores específicos de virulência têm sido relacionados com fenótipos de resistência cujos padrões parecem variar de acordo com a população em estudo ${ }^{79}$. A emergência de amostras resistentes 
aos antimicrobianos tradicionais empregados no tratamento das ITUs, como o sulfametaxazol-trimetoprim, tem recomendando o uso de terapias alternativas ${ }^{3}$. Dos 13 antimicrobianos testados, foi detectada resistência em $63 \%$ das amostras de Escherichia coli isoladas de indivíduos atendidos no CSEGSF/ENSP/FIOCRUZ, com índices de 5,2\% (ciprofloxacina), 42,1\% (sulfazotrim/trimetoprim) e 52,6\% (ampicilina). Entre as amostras isoladas de mulheres grávidas, foi detectada resistência para gentamicina (14,2\%), ampicilina (28,5\%) e sulfazotrim/trimetoprim (42,8\%). Entre aquelas obtidas de mulheres não-grávidas, foi observada resistência a gentamicina/ciprofloxacina (12,5\%), ácido nalidíxico $(25 \%)$, sulfazotrim/trimetoprim $(37,5 \%)$ e a ampicilina $(62,5 \%)$. Neste grupo de indivíduos, o fenótipo de multi-resistência para até 3 antimicrobianos foi detectado em 52,6\% das amostras. Todas as amostras se apresentaram susceptíveis a: ceftazidima, fosfomicina, nitrofurantoína e piperacilina + tazobactam. Resistência intermediária foi detectada para amicacina e cefotaxina (5,2\%) e ácido clavulânico + amoxicilina (10,5\%). Para a população atendida no HU/UFRJ, a resistência foi detectada em $71,4 \%$ das amostras com índices de 4,7\% (gentamicina), 14,2\% (ácido clavulânico + amoxicilina/nitrofurantoína), 23,8\% (ciprofloxacina), 28,5\% (ácido nalidíxico) e 52,3\% (ampicilina/sulfazotrim/trimetoprim). Neste grupo, foi detectada multi-resistência para 2 a 6 antimicrobianos e apenas entre amostras isoladas de pacientes com uso prévio de antibióticos. Todas as amostras foram susceptíveis para amicacina e cefotaxima. Resistência intermediária foi detectada para ceftazidima $(4,7 \%)$, fosfomicina $(9,5 \%)$ e piperacilina + tazobactam $(4,7 \%)$. Das amostras obtidas de pacientes com quadro de pielonefrite, $42,8 \%$ foram sensíveis aos antimicrobianos testados e os demais apresentaram resistência para gentamicina/nitrofurantoína (14,2\%), ampicilina/ciprofloxacina/trimetoprim $(25,5 \%)$ e para 0 ácido nalidíxico/sulfazotrim (42,8\%). As amostras isoladas de pacientes com infecção assintomática apresentaram resistência para o ácido nalidíxico/ciprofloxacina (16,6\%), nitrofurantoína (33,3\%), ampicilina/trimetoprim (50\%) e para o sulfazotrim (66,6\%). Dentre as amostras isoladas de pacientes com ITU baixo, foi observada resistência para ácido nalidíxico/ ciprofloxacina/nitrofurantoína (16,6\%), ácido clavulânico + amoxicilina/sulfazotrim (50\%) e para ampicilina/trimetoprim (66,6\%). Das amostras que apresentaram resistência a pelo menos um dos antimicrobianos testados, 32\% apresentaram MRHA, 35,7\% expressaram o tipo beta hemolítico e 64,3\% o tipo alfa hemolítico. De um modo geral, amostras pertencentes a um mesmo sorotipo apresentaram o mesmo padrão de susceptibilidade aos antimicrobianos. 0 sistema de tipagem empregado apresentou um elevado poder discriminatório, permitindo detectar uma população bacteriana composta por 39 tipos eletroforéticos distintos (Figura 1). Todos as enzimas investigadas foram polimórficas, com número de eletromorfos variando de 3 (ACO, MDH, PGM e IDH) a 6 (PGD). 0 agrupamento obtido a partir da eletroforese de isoenzimas revelou a presença de três grupos clonais principais e uma relação mais estreita entre amostras de UPEC que compartilham características hemolíticas e antigênicas. Não foi observada uma associação significativa com os outros marcadores investigados.

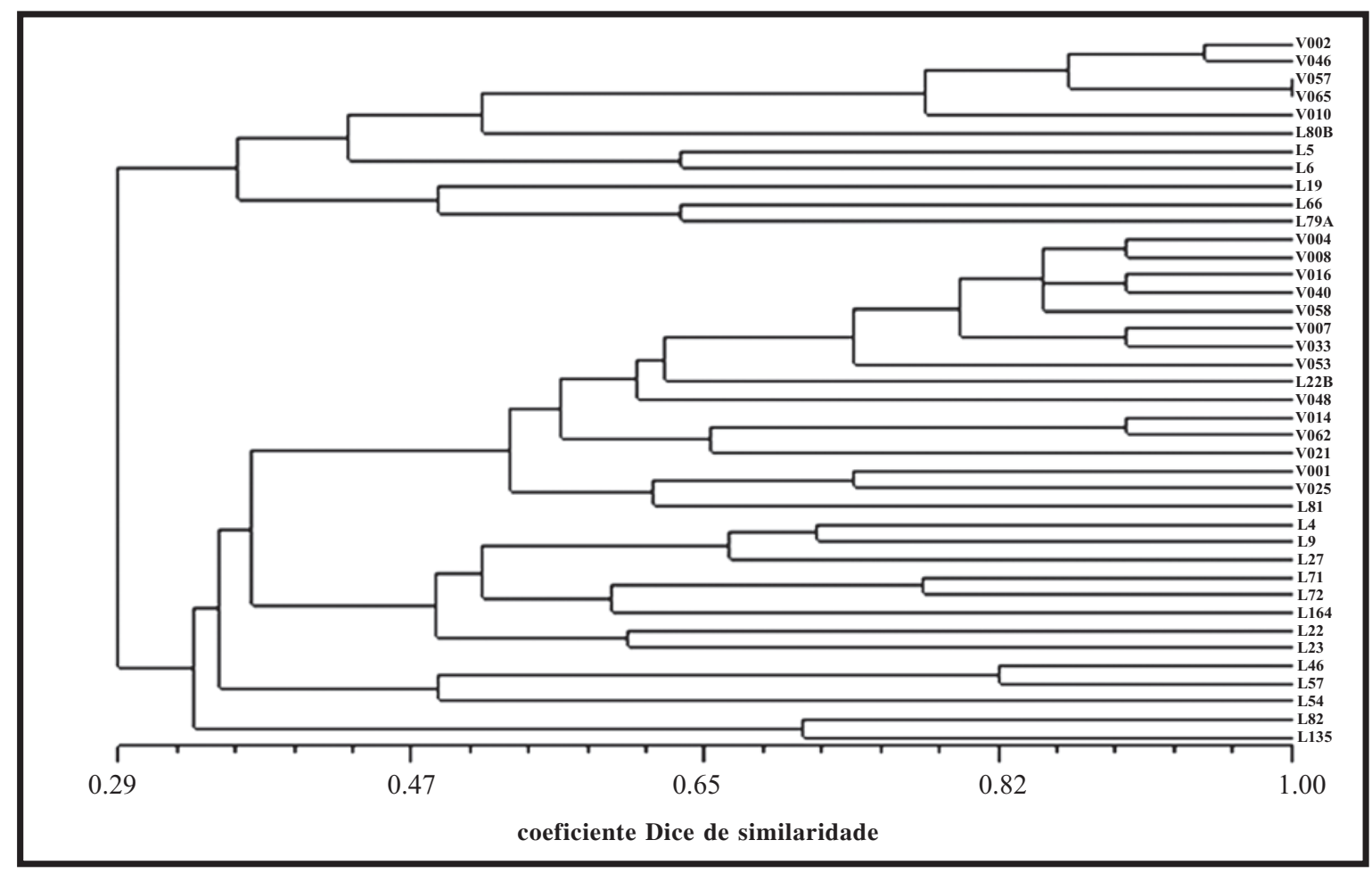

Figura 1- Dendrograma resultante da análise da eletroforese de isoenzimas de amostras uropatogênicas Escherichia coli (UPEC) incluídas no estudo. 
A heterogeneidade comumente descrita em populações uropatogênicas de $E$. coli, tem dificultado a detecção da emergência e da circulação de linhagens patogênicas ${ }^{2}$. Variações nas características populacionais e geográficas, são descritas como fatores que contribuem para esta diversidade. Este aspecto foi considerado em nosso estudo, uma vez que, as amostras foram isoladas de localidades e períodos distintos. Apesar desta diversidade, características comuns também foram detectadas entre amostras epidemiologicamente não-relacionadas, sugerindo a disseminação de subpopulações clonais. A ampla distribuição destes marcadores, incluindo os determinantes de resistência, alerta para a necessidade de uma vigilância mais efetiva, com $o$ intuito de detectar tanto a emergência de variantes virulentas quanto a transmissão e a disseminação de propriedades específicas de virulência para organismos dispersos na comunidade. Tal abordagem é também de grande aplicabilidade na recomendação de estratégias envolvendo esquemas terapêuticos específicos, além de reduzir os custos e a incidência de efeitos adversos. 0 conjunto dos dados obtidos traz uma contribuição para o esclarecimento dos aspectos biológicos e das relações epidemiológicas destes uropatógenos circulantes na comunidade, o que é especialmente relevante, considerando a limitação destas informações em nosso meio.

\section{REFERÊNCIAS BIBLIOGRÁFICAS}

1. Brauner A, Katouli M, Tullus K, Jacobson SH. Production of cytotoxic necrotizing factor, verocytotoxin and haemolysin by pyelonephritogenic
Escherichia coli. European Journal of Clinical and Medical Microbiology Infectious Diseases 9: 762-767, 1990.

2. Foxman B, Riley L. Molecular epidemiology: focus on infection. American Journal of Epidemiology 153: 1135-114, 2001

3. Helberg IP, Schor N. Abordagem diagnóstica e terapêutica na infecção do trato urinário. Revista da Associação Médica Brasileira 49: 109-116, 2003.

4. Johnson JR. Virulence factors in Escherichia coli urinary tract infection. Clinical Microbiology Review 4: 80-128, 1991.

5. Johnson JR. Microbial virulence determinants and the pathogenesis of urinary tract infection. Infectious Diseases Clinics of North America 17: 261-278, 2003

6. Johnson JR, Manges AR, O'Bryan TT, Riley LW. A disseminated multidrug resistant clonal group of uropathogenic Escherichia coli in pyelonephritis. The Lancet 359: 2249-2251, 2002.

7. Kachroo BB. Association between antibiotic resistance and the expression of Dr adhesin among uropathogenic Escherichia coli. Chemotherapy 47: 97-103, 2001.

8. Kaper JB, Nataro JP, Mobley HL. Pathogenic Escherichia coli. Nature Reviews Microbiology 2: 123-140, 2004.

9. Naveen R, Mathai E. Some virulence characteristics of uropathogenic Escherichia coli in different patient groups. Indian Journal of Medical Research 122: 143-147, 2005.

10. Nimmich W, Voigt W, Seltmann G. Characterization of urinary Escherichia coli 075 strains. Journal of Clinical Microbiology 35: 1112-1117, 1997.

11. Sannes MR, Kuskowski MA, Johnson JR. Geographical distribution of antimicrobial resistance among Escherichia coli causing acute uncomplicated pyelonephritis in the United States. FEMS Immunology and Medical Microbiology 42: 213-218, 2004.

12. Siegfried L, Kmetová M, Puzová H, Molokacová, Filka J. Virulenceassociated factors in Escherichia coli strains isolated from children with urinary tract infections. Journal of Medical Microbiology 41: 127-132, 1994 